\title{
AKTIVITAS ANTIJAMUR DAN IDENTIFIKASI METABOLIT SEKUNDER ISOLAT JAMUR ENDOFIT DARI DAUN YAKON (SMALLANTHUS SONCHIFOLIUS) TERHADAP BEBERAPA JAMUR PATOGEN
}

\author{
Aditya Fridayanti, Arsyik Ibrahim, Fitriyani* \\ Laboratorium Penelitian dan Pengembangan FARMAKA TROPIS, \\ Fakultas Farmasi Universitas Mulawarman, Samarinda, Kalimantan Timur \\ *Email:piteenah@gmail.com
}

\begin{abstract}
Each plant is host to one or more endophytes contain bacteria and fungi. Endophytic fungi could potentially have an activity and produce secondary metabolites same as its host. Yacon leaf (Smallanthus sonchifolius) has been known to have antimicrobial activity that allow the endophytic fungi also has potential as antimicrobial. The purpose of this research was to isolated the endophytic fungi from Yacon leaf which has activity as antifungal and can produce secondary metabolites same as its host. The method that used to test the activity of endophytic fungi are using direct planting method, whereas the identification of secondary metabolites using Thin Layer Chromatography (TLC) and spray reagent. The results were obtained that the endophytic fungi has an activity as antifungal against Candida utilis, Candida albicans and Malassezia Purpur, along with the presence of secondary metabolites that same as its host.
\end{abstract}

Key words: endophytic fungi, Smallanthus sonchifolius, antifungal, Thin Layer Chromatography (TLC)

\begin{abstract}
ABSTRAK
Setiap tanaman mengandung satu atau lebih mikroba endofit yang terdiri dari bakteri dan jamur. Jamur endofit berpotensi memiliki aktivitas dan menghasilkan metabolit sekunder yang sama seperti inangnya. Daun Yakon (Smallanthus sonchifolius) telah diketahui memiliki aktivitas sebagai antimikroba sehingga memungkinkan adanya jamur endofit yang juga berpotensi sebagai antimikroba. Tujuan dari penelitian ini adalah didapatkan isolat jamur endofit dari daun Yakon yang memiliki aktivitas sebagai antijamur dan dapat menghasilkan metabolit sekunder yang sama seperti inangnya. Metode yang digunakan untuk menguji aktivitas isolat jamur endofit adalah menggunakan metode tanam langsung, sedangkan identifikasi metabolit sekunder menggunakan metode Kromatografi Lapis Tipis (KLT) dan pereaksi semprot. Hasil penelitian yang diperoleh adalah adanya isolat jamur endofit yang memiliki aktivitas sebagai antijamur terhadap jamur Candida utilis, Candida albicans, dan Malassezia purpur, serta adanya metabolit sekunder yang sama seperti inangnya.
\end{abstract}

Kata kunci: Jamur endofit, Smallanthus sonchifolius, antijamur, Kromatografi Lapis Tipis (KLT) 


\section{PENDAHULUAN}

Beberapa tahun terakhir, gaya hidup kembali ke alam (back to nature) sangat populer sehingga banyak masyarakat memanfaatkan bahan-bahan alam untuk terapi pengobatan. Banyak tanaman yang telah ditelaah dan dipelajari secara ilmiah terbukti mengandung zat-zat atau senyawa yang secara klinis bermanfaat bagi kesehatan.

Salah satu tanaman yang telah terbukti secara klinis bermanfaat bagi kesehatan adalah Yakon. Yakon (Smallanthus sonchifolius) merupakan tanaman asli dari dataran tinggi Andes di Amerika Selatan yang selama berabadabad telah digunakan untuk makanan maupun obat tradisional. Di Indonesia sendiri, tanaman Yakon belum banyak dikenal karena penyebarannya yang masih kurang di masyarakat. Daun Yakon di Indonesia lebih dikenal sebagai daun insulin, hal ini karena secara empiris daun Yakon telah banyak digunakan untuk mengobati penyakit Diabetes Melitus. Akibat penyebarannya yang masih kurang tersebut, belum banyak penilitian terkait tanaman Yakon yang dilakukan di Indonesia.

Berdasarkan beberapa penelitian yang telah dilakukan di beberapa negara lain, daun Yakon telah terbukti memiliki aktivitas antimikroba [1], antihiperglikemia, antioksidan, dan antifungi [2], serta mengandung metabolit sekunder berupa kaurene diterpenoids, acetophenone-type phytoalexins, dan melampoilde-type sesquiterpene lactones [1]. Informasi tersebut telah cukup untuk dijadikan sebagai acuan adanya berbagai aktivitas serta kandungan metabolit sekunder yang terdapat di dalam daun Yakon.

Salah satu cara terbaru untuk mendapatkan metabolit sekunder tanpa mengeksploitasi tumbuhan asalnya secara besar-besaran adalah dengan menggunakan mikroba endofit yang hidup di dalam jaringan tanaman. Endofit adalah organisme yang hidup di dalam organ tanaman dan kadang-kadang dapat membentuk koloni di dalam jaringan tanaman tanpa menyebabkan kerugian pada inangnya [3]. Dari sekitar 300.000 jenis tanaman yang tersebar di muka bumi ini, masing-masing tanaman mengandung satu atau lebih mikroba endofit yang terdiri dari bakteri dan jamur [4]. Berdasarkan hal tersebut, penulis tertarik untuk mengisolasi jamur endofit dari daun Yakon (Smallanthus sonchifolius) untuk selanjutnya diuji aktivitasnya sebagai antijamur serta diidentifikasi metabolit sekundernya.

\section{METODE PENELITIAN}

\section{Bahan}

Bahan-bahan yang digunakan dalam penelitian ini antara lain adalah medium PDA, medium PDB, Kloramfenikol, Etanol $70 \%, \mathrm{NaOCl}$, Metanol, Kloroform, air suling, kertas saring, pereaksi semprot $\mathrm{H}_{2} \mathrm{O}_{2} 3 \%$, pereaksi Liebermann-Burchard, pereaksi Dragendroff, Sitroborat, Asam Fosfat 85 $\%$, dan Timbal Asetat.

\section{Peralatan}

Peralatan yang digunakan dalam penelitian ini antara lain adalah oven, autoklaf, Laminar Air Flow, rotary shaker, refrigerator, inkubator, sentrifus, lemari asam, tabung sentrifus, timbangan digital, corong, labu Erlenmeyer, gelas kimia, cawan Petri, pembakar spiritus, waterbath, gelas ukur, pipet volume, pinset, mikropipet, spatula, gunting, pisau steril (bisturi), chamber, ose bulat.

\section{Prosedur Penelitian}

\section{Isolasi Jamur Endofit}

Daun Yakon yang digunakan untuk isolasi jamur endofit diambil secara random (acak) dan dipetik langsung dari tanamannya dalam bentuk segar dengan kriteria daun tua (bukan yang sudah menguning atau agak mengering). Isolasi jamur endofit dilakukan dengan metode 
tanam langsung. Sebelumnya, daun Yakon terlebih dahulu dicuci dengan air mengalir. Setelah pencucian, dilakukan sterilisasi permukaan dengan merendam sampel di dalam alkohol $75 \%$ selama 1 menit, larutan $\mathrm{NaOCl} 5,3 \%$ selama 3 menit, dan direndam kembali di dalam alkohol $75 \%$ selama 1 menit, kemudian dibiarkan mengering dalam LAF (Laminar Air Flow). Setelah itu dilakukan pemotongan menggunakan alat potong steril dengan ukuran $1 \times 1 \mathrm{~cm}$ dan dibuka jaringannya secara horizontal kemudian ditempelkan di atas media Potato Dextrose Agar (PDA) yang telah ditambahkan kloramfenikol $100 \mu \mathrm{g} / \mathrm{mL}$. Pengamatan dilakukan setiap hari sampai tampak jamur yang tumbuh ( $\pm 7-14$ hari).

Jamur endofit yang tumbuh pada media di atas, dimurnikan masing-masing pada media PDA baru yang juga ditambahkan kloramfenikol (PDAC). Kemudian diinkubasi kembali selama 714 hari pada suhu ruang. Setelah inkubasi, dilakukan pengamatan terhadap bentuk dan warna koloni pada media tersebut, setiap koloni yang berbeda bentuk dan warnanya berdasarkan pengamatan makroskopis diisolasi kembali pada media PDAC dan diinkubasi pada kondisi yang sama seperti sebelumnya hingga didapatkan isolat jamur endofit (IJE).

\section{Uji Aktivitas Antijamur}

Uji aktivitas antijamur dilakukan dengan menggunakan metode tanam langsung. Pengujian dilakukan dengan terlebih dahulu membuat suspensi jamur uji dengan perbandingan 1:20. Disiapkan pula IJE yang telah dipotong menggunakan pisau steril dengan ukuran $\pm 2 \times 2 \mathrm{~mm}$. Selanjutnya, dimasukkan 0,02 $\mathrm{mL}$ suspensi jamur uji dan $10 \mathrm{~mL}$ media PDA ke dalam cawan petri kemudian dihomogenkan. Potongan IJE dimasukkan ke dalam cawan petri ketika medium telah setengah memadat. Pengujian dilakukan dengan tiga ulangan.
Kemudian diinkubasi selama 3 hari di dalam inkubator pada suhu $37^{\circ} \mathrm{C}$.

\section{Produksi Metabolit Sekunder}

Sebelum proses produksi metabolit sekunder, isolat jamur endofit yang telah diperoleh terlebih dahulu dibenihkan di dalam $50 \mathrm{~mL}$ media Potato Dextrose Broth (PDB) dalam labu Erlenmeyer dan diinkubasi selama 7 hari pada suhu ruang. Hasil pembenihan isolat jamur endofit yang diperoleh kemudian diambil $5 \mathrm{~mL}$ volumenya dan dimasukkan ke dalam $250 \mathrm{~mL}$ media PDB yang telah ditambahkan pecahan beling dalam labu Erlenmeyer dan diinkubasi dengan penggoncangan menggunakan shaker selama 5-7 hari pada suhu ruang. Hasil inkubasi kemudian disaring menggunakan kertas saring Whatmann no. 41. Filtrat yang diperoleh kemudian disentrifugasi dengan kecepatan 6.000 rpm selama 20 menit. Miselia yang tertinggal pada kertas saring setelah proses penyaringan serta miselia yang mengendap setelah proses sentrifugasi kemudian dicampurkan dan dikeringkan selama 4 jam di dalam oven dengan suhu $40{ }^{\circ} \mathrm{C}$. Miselium kering selanjutnya diekstraksi menggunakan metanol selama 2 hari, ekstrak yang diperoleh dikeringkan di atas waterbath hingga kering. Ekstrak kering tersebut yang kemudian akan digunakan untuk identifikasi golongan metabolit sekunder.

\section{Identifikasi Metabolit Sekunder}

Identifikasi metabolit sekunder dilakukan secara kualitatif menggunakan metode Kromatografi Lapis Tipis (KLT). Ekstrak jamur endofit yang diperoleh terlebih dahulu dilarutkan di dalam metanol, kemudian ditotolkan pada plat KLT yang telah diaktifkan. Plat KLT yang telah ditotol kemudian dielusi dengan eluen yang telah dijenuhkan di dalam chamber. Selanjutnya diamati profil bercak noda pada UV $254 \mathrm{~nm}$ dan $366 \mathrm{~nm}$. Setelah diamati, plat KLT disemprot dengan beberapa pereaksi 
semprot antara lain pereaksi Sitroborat dan Timbal Asetat untuk uji flavonoid, pereaksi Liebermann Bouchardat untuk uji terpenoid, pereaksi Dragendroff untuk uji alkaloid, pereaksi $\mathrm{H}_{2} \mathrm{O}_{2}$ untuk uji asam aromatis, serta pereaksi Asam Fosfat $85 \%$ untuk uji steroid. Reaksi positif menggunakan pereaksi Sitroborat dan Timbal Asetat akan menghasilkan fluoresensi kuning-hijau pada sinar UV $366 \mathrm{~nm}$, dengan pereaksi Liebermann Bouchardat akan menghasilkan fluoresensi biru pada sinar UV $366 \mathrm{~nm}$, dengan pereaksi $\mathrm{H}_{2} \mathrm{O}_{2}$ akan menghasilkan fluoresensi biru pada sinar UV $366 \mathrm{~nm}$, dengan pereaksi Dragendroff akan menghasilkan fluoresensi jingga-coklat dan merah-jingga dengan latar belakang hitam pada sinar UV $366 \mathrm{~nm}$, serta dengan pereaksi $\mathrm{H}_{2} \mathrm{O}_{2}$ akan menghasilkan fluoresensi biru pada sinar UV $366 \mathrm{~nm}$,

\section{HASIL DAN PEMBAHASAN}

\section{Isolasi Jamur Endofit}

Beberapa metode untuk mengisolasi jamur endofit telah banyak dijelaskan dalam berbagai literatur. Metode yang umum dan telah banyak digunakan adalah dengan melakukan sterilisasi permukaan bagian tanaman menggunakan alkohol $70 \%$ dan $\mathrm{NaOCl}$ (natrium hipoklorit) 5,3\%. Bagian tanaman yang telah steril kemudian ditempelkan di atas media pertumbuhan, dalam hal ini adalah media Potato Dextrose Agar (PDA) yang telah ditambahkan Kloramfenikol berfungsi untuk menghambat pertumbuhan bakteri endofit maupun bakteri kontaminan. Pengamatan dilakukan selama masa inkubasi untuk memastikan adanya jamur endofit yang tumbuh di sekitar bagian tanaman. Koloni jamur yang tumbuh kemudian dimurnikan kembali di dalam media PDA yang juga ditambahkan Kloramfenikol hingga diperoleh isolat murni berupa pertumbuhan tunggal dengan karakteristik warna dan bentuk koloni yang berbeda pada setiap isolat.

Isolasi dilakukan dengan 3 kali pengulangan untuk memastikan bahwa jamur yang tumbuh di sekitar bagian daun adalah jamur endofit dari tanaman tersebut dan bukan kontaminasi. Hasil yang sama setiap pengulangan meyakinkan peneliti bahwa jamur endofit telah berhasil diisolasi dari daun Yakon (Smallanthus sonchifolius).

IJE yang telah berhasil diisolasi dari daun Yakon berjumlah 2 isolat, yaitu ScFR-1 dan ScFR-2. Berdasarkan pengamatan makroskopis, dapat terlihat bahwa permukaan isolat ScFR-1 berwarna hitam dengan tepi berwarna putih dan bentuk koloni berserabut, sedangkan permukaan isolat ScFR-2 berwarna putih dengan bentuk koloni berserabut pula.

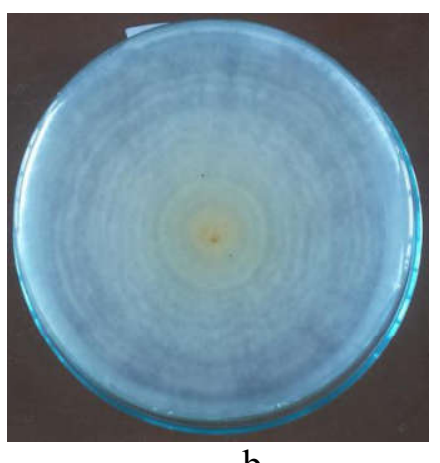

b

Gambar 1. Hasil isolasi jamur endofit (a) ScFR-1 dan (b) ScFR-2. 
2. Uji Aktivitas Antijamur

Uji aktivitas antijamur dilakukan dengan menggunakan metode tanam langsung. Uji ini dilakukan untuk mengetahui aktivitas IJE sebagai antijamur secara kualitatif terhadap beberapa jamur patogen, antara lain Candida utilis, Candida albicans, dan Malassezia purpur. Uji ini juga dapat digunakan sebagai langkah awal sebelum melakukan proses produksi metabolit sekunder, hal ini untuk memastikan bahwa metabolit sekunder yang diproduksi memiliki aktivitas sebagai antimikroba.

Uji aktivitas antijamur IJE memperlihatkan bahwa isolat ScFR-1 tidak memiliki aktivitas antijamur terhadap jamur uji, sedangkan isolat ScFR-2 memperlihatkan aktivitas yang cukup besar dalam menghambat pertumbuhan jamur uji bahkan hingga membentuk zona bunuh.

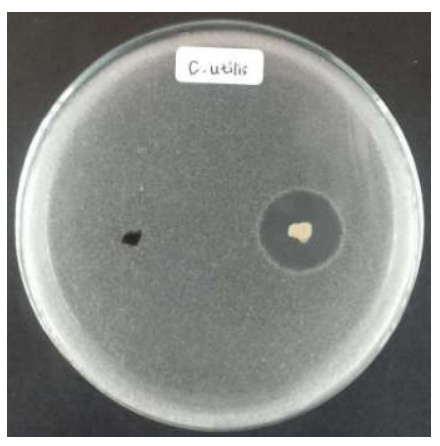

a

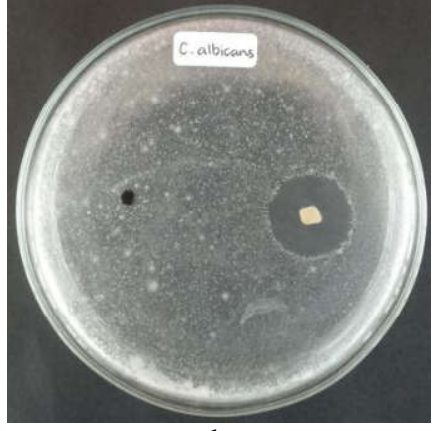

$\mathrm{b}$

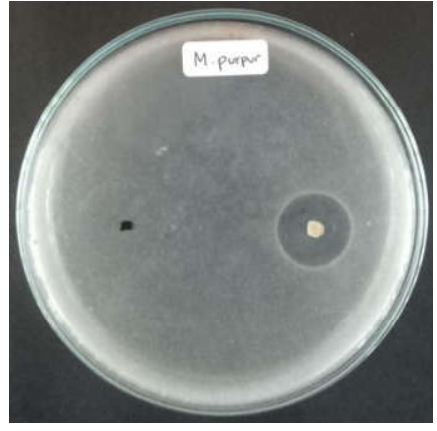

$\mathrm{C}$

Gambar 2. Hasil uji aktivitas antijamur isolat ScFR-1 dan ScFR-2 terhadap jamur (a) Candida utilis, (b) Candida albicans, dan (c) Malassezia purpur.

3. Identifikasi Metabolit Sekunder Identifikasi metabolit sekunder dilakukan secara kualitatif menggunakan metode Kromatografi Lapis Tipis (KLT). Golongan metabolit yang ingin diidentifikasi antara lain adalah alkaloid, flavonoid, steroid, asam aromatis, dan terpenoid.

Metabolit sekunder golongan alkaloid, flavonoid, dan asam aromatis tidak terdeteksi pada saat skrining, hal ini dapat disebabkan karena tidak diproduksinya metabolit sekunder tersebut oleh isolat ScFR-1 dan ScFR-2 Belum ada studi literatur yang menyatakan bahwa daun Yakon mengandung metabolit-metabolit sekunder tersebut. Berbeda dengan skrining metabolit sekunder golongan steroid dan terpenoid yang terdeteksi di dalam ekstrak isolat ScFR-1 dan ScFR-2.

Tabel 1. Identifikasi Metabolit Sekunder

\begin{tabular}{cllcc}
\hline \multirow{2}{*}{ No. } & Golongan Metabolit & \multicolumn{2}{c}{ Pereaksi Semprot } & \multicolumn{2}{c}{ Hasil } \\
\cline { 3 - 5 } & \multicolumn{1}{c}{ Sekunder } & & ScFR-1 & ScFR-2 \\
\hline 1. & Alkaloid & Dragendroff & - & - \\
2. & Flavonoid & Timbal Asetat & - & - \\
3. & Flavonoid & Sitroborat & - & - \\
4. & Steroid & Asam Fosfat $85 \%$ & + & + \\
5. & Asam Aromatis & $\mathrm{H}_{2} \mathrm{O}_{2}$ & - & - \\
6. & Terpenoid & Liebermann Bouchardat & + & + \\
\hline
\end{tabular}

Keterangan: $+=$ mengandung metabolit sekunder

- = tidak mengandung metabolit sekunder 


\section{KESIMPULAN DAN SARAN}

1. Isolat jamur endofit ScFR-1 dari daun Yakon (Smallanthus sonchifolius) memiliki aktivitas sebagai antijamur terhadap Candida utilis, Candida albicans, dan Malassezia purpur, sedangkan isolat ScFR-2 tidak.

2. Golongan metabolit sekunder yang dihasilkan oleh ScFR-1 dan ScFR-2 adalah steroid dan terpenoid.

\section{DAFTAR PUSTAKA}

1. Choi, J.G., O.H. Kang, Y.S. Lee, Y.C. Oh, H.S. Chae, B. Obiang-Obounou, S.C. Park, D.W. Shin, B.Y. Hwang, dan D.Y. Kwon. 2010. Antimicrobial Activity of the Constituents of Smallanthus sonchifolius Leaves Against Methicillin-Resistant Staphylococcus aureus. European Review for Medical and
Pharmacological Sciences. 14. 10051009.

2. Hong, S.S., S.A. Lee, X.H. Han, M.H. Lee, J.S. Hwang, J.S. Park, K.W. Oh, K. Han. M.K. Lee, H. Lee, W. Kim, D. Lee, dan B.Y. Hwang. Melampolides from the Leaves of Smallanthus sonchifolius and Their Inhibitory Activity of LPS-Induced Nitric Oxide Production. Chem Pharm Bull. 56 (2). 199-202.

3. Varma, A., L. Abbott, D. Warner, R. Hampp. 2008. Plant Surface Microbiology. Springer-Verlag Berlin Heidelberg. New York.

4. Strobel, G.A. dan B. Daisy. 2003. Bioprospecting for Microbial Endophytes and Their Natural Products. Microbiology and Molecular Biology Reviews. 67. (4). 491-502. 